\title{
DEVELOPMENT AND CHARACTERIZATION OF POMEGRANATE AND ORANGE FRUIT PEEL EXTRACT BASED SILVER NANOPARTICLES
}

\author{
Vinay $\mathrm{C}^{1 *}$, Goudanavar $\mathrm{P}^{1}$, Acharya $\mathrm{A}^{1}$ \\ ${ }^{1}$ Department of Pharmaceutics, Sri Adichunchanagiri College of Pharmacy, B.G. Nagara, \\ Karnataka -571448, India. \\ *Corresponding Author:
}

Vinay C H, Research Scholar, Department of Pharmaceutic, Sri Adichunchanagiri College of Pharmacy, B.G. Nagar, Karnataka, India. E. mail : vinaykalyani9743@gmail.com

\section{ABSTRACT}

Background: Nanoparticles are those whose size ranges $1 \mathrm{~nm}$ to $100 \mathrm{~nm}$. They are in different sizes and shape, such as triangular, spherical, irregular, etc. In recent years, nanoparticles synthesis has received considerable attention due to their unique properties and potential applications. Powdered sample $(100 \mathrm{gm})$ was extracted with $800 \mathrm{ml}$ ethanol by Soxhlet extraction method for 6 hours. The resultant extract was used to prepare nanoparticles.

Methods: The main objective of the present work was to prepare pomegranate and orange peel extract based nano particles by chemical complexation method. Ethanolic extracts of pomegranate and orange peel were prepared by using Soxhlet apparatus and evaluated for phyto-chemical constituents.

Results: Qualitative analysis of pomegranate peel showed positive results for Alkaloids, Anthraquinones, Saponins and Terpenoids, where as orange peel showed positive results for Alkaloids, Tannin and Saponins. The percentage moisture content obtained from the 2 fruits (pomegranate and orange) was $72 \%$ and $96.12 \%$ respectively. The $\mathrm{pH}$ was found to be 3.6 and 3.8 for pomegranate and orange respectively. A zeta potential of prepared nanoparticles for pomegranate extract was found in the range of $-24.6 \mathrm{mV}$ to $-34.5 \mathrm{mV}$ (P20 \& P50) and $21.4 \mathrm{mV}$ to $32.0 \mathrm{mV}(\mathrm{O} 20 \& \mathrm{O} 50)$ for orange extract, respectively. These values of nanoparticles having higher surface charge which indicates there is least chance of aggregation. The particle size for pomegranate extract was found in the range of $118.6 \mathrm{~nm}$ to $231.7 \mathrm{~nm}$ (P20 \& P30) and $178.8 \mathrm{~nm}$ to $191.6 \mathrm{~nm}(\mathrm{O} 20$ \& O50) for orange extract, respectively. These range confirms that obtained particles were in nano range, i.e. $<500 \mathrm{~nm}$ size. SEM results indicated the formation of nanoparticles and were relatively spherical in shape. Energy dispersive spectrometry (EDS) analysis confirms the presence of AgNPs.

Conclusion: The silver nanoparticles were prepared by using fruit peels extract of pomegranate and orange. Computability study FT-IR showed no any change of functional groups of peel extracts in prepared nanoparticles. Zeta potential showed higher value hence less particle aggregation. Prepared nanoparticles were spherical in shape and having particle size of approximately $200 \pm 20 \mathrm{~nm}$. Further the study will be extended for anti-microbial and wound healing activities.

Key words: Orange peel extract, Qualitative analysis, Nano particles, Zeta potential, Particle Size. 


\section{INTRODUCTION}

Nanoparticles are those whose size ranges $1 \mathrm{~nm}$ to $100 \mathrm{~nm}$. They are in different sizes and shape, such as triangular, spherical, irregular, etc. In recent years, nanoparticles synthesis has received considerable attention due to their unique properties and potential applications ${ }^{1}$.

Nanoparticles exhibit completely new or improved properties compared with larger particles of the bulk materials and these novel properties are derived due to the variation in specific characteristics such as size, distribution and morphology of the particles. Nanoparticles present a higher surface area to volume ration with decrease in the size of the particles ${ }^{2}$.

Nanoparticles can be synthesized using various approaches including chemical, physical, and biological. Although chemical method of synthesis requires short period of time for synthesis of large quantity of nanoparticles, this method requires capping agents for size stabilization of the nanoparticles. Chemicals used for nanoparticles synthesis and stabilization are toxic and lead to non-ecofriendly by-products. The need for environmental non-toxic synthetic protocols for nanoparticles synthesis leads to the developing interest in biological approaches which are free from the use of toxic chemicals as by-products. Thus, there is an increasing demand for green nanotechnology. Plants provide a better platform for nanoparticles synthesis as they are free from toxic chemicals as well as provide natural capping agents ${ }^{3}$.

Pomegranate peel is a rich source of tannins, flavonoids, polyphenols and some anthocyanins as delphinidins, cyanidins, etc. Antioxidant and antibacterial properties of pomegranate peel in in-vitro model systems have been reported. All the compounds of pomegranate peels are reported to have therapeutic properties. Extracts of peels of pomegranate show antibacterial property against bacterial strains of E. coli, P. aeruginosa and $S$. Aureus ${ }^{4}$.

Citrus sinensis is genus of flowering plants in the family Rutaceae. Orange peels are a boon for skin, as they possess anti-microbial, anti-inflammatory and anti-fungal properties. The dried peels can be powdered and used to scrub and exfoliate skin. It is a great cleanser, helps to cure acne and pus filled pimples and remove blackheads, dark spots and pigmentation ${ }^{5}$.

The aim of the present study was to synthesize the pomegranate and orange fruit peel extract based nano particle

\section{MATERIALS AND METHODS}

\section{Materials used}

Pomegranate and orange peels were collected from local market, Bellur. Chemicals like Silver nitrate and Sodium borohydride were obtained from S.D Fine chemicals, Mumbai, India. All others chemical used were analytical grade. Milli Q water was used throughout the experiment.

\section{Methods used}

\section{Nanoparticles Preparation}

Fruits of pomegranate and orange were collected, peels were separated and washed thoroughly with tap water. The washed peels were cut in to small pieces $[1-5 \mathrm{~cm}]$ and air dried in sunlight for 20 days. The dried fruit peels were grinded properly using a mortar and pestle and later using a grinder, to obtain the powdered form and then passed through sieve no. 40 to get uniform powder and stored at room temperature. Powdered sample (100gm) was 
extracted with $800 \mathrm{ml}$ ethanol by Soxhlet extraction method for 6 hours. The mixture filtered through a Whatman filter paper (No. 2) for removal of peel particles. The extracts were filtered and evaporated to dryness under reduced pressure at $60^{\circ} \mathrm{C}$ by a rotary evaporator (Buchi, Singapore). The extracts were placed in dark bottles and stored in refrigerator at $4^{\circ} \mathrm{C}^{6}$.

To a $50 \mathrm{ml}$ of freshly prepared $0.001 \mathrm{M}$ Silver nitrate solution, $5 \mathrm{ml}$ of $0.002 \mathrm{M}$ Sodium borohydride solution was added with continuous stirring and kept it aside for 15 minutes in a clean $250 \mathrm{ml}$ beaker till a clear and slightly dark solution is obtained. Further, this clear solution is heated and maintained in water bath at $45^{\circ} \mathrm{C}$ for $30 \mathrm{~min}$ (solution A). Pomegranate peel extract in different concentration i.e. 200mg (P20), and 500mg (P50) was dissolved in $4 \mathrm{ml}$ of Milli Q water separately in test tube and heated slightly to get yellow brownish colored solution. This solution was added drop wise into solution A with continuous stirring using glass rod for 30-45 min till clear tea brown solution is obtained. The obtained solution is cooled to room temperature and $0.5 \mathrm{ml}$ of $0.5 \mathrm{mcg} / \mathrm{ml}$ PVP solution was added as a stabilizer and filtered to get clear tea brown colored solution of silver nanoparticles. This solution was stored in a dark place in a well closed container until further use. The same procedure was followed even for the orange peel extract to get clear orange color solution of silver nanoparticles.Then prepared nanoparticles were evaluated for FTIR, particle size, zeta potential, surface morphology by SEM, X-ray diffraction and energy dispersive spectrometry ${ }^{7}$.

\section{RESULTS AND DISCUSSION}

Pomegranate and orange peel extracts were subjected to various tests to confirm the presence of photochemical constituents. The UV-spectroscopic analysis showed that pomegranate peel extract, a colored solution showed maximum absorbance at $461 \mathrm{~nm}$ wave length ${ }^{8}$ (figure 1). This result is in agreement with Nisha MH et al. studies, where they reported maximum absorbance of at pomegranate peel $472 \mathrm{~nm} .{ }^{9}$ Whereas orange peel extract showed absorbance at $280 \mathrm{~nm}$ wave length (figure 2). Hence same wave length will be used for further studies. Results of qualitative analysis reviled that pomegranate peel extract showed positive results for Alkaloids, Anthraquinones, Saponins, tannins, and Terpenoids ${ }^{10}$, where as orange peel showed positive results for Alkaloids, Tannin and Saponins ${ }^{11}$. The results were tabulated in table 1. Quantitative analysis reviled that equivalent weight in $\mathrm{mg} / \mathrm{ml}$ found to be 345.14 and 500.10 respectively. The percentage moisture content obtained from the 2 fruits (pomegranate and orange) was $72 \%$ and $96.12 \%$ respectively. The $\mathrm{pH}$ was found to be 3.6 and 3.8 for pomegranate and orange respectively. The results were tabulated in table 2.

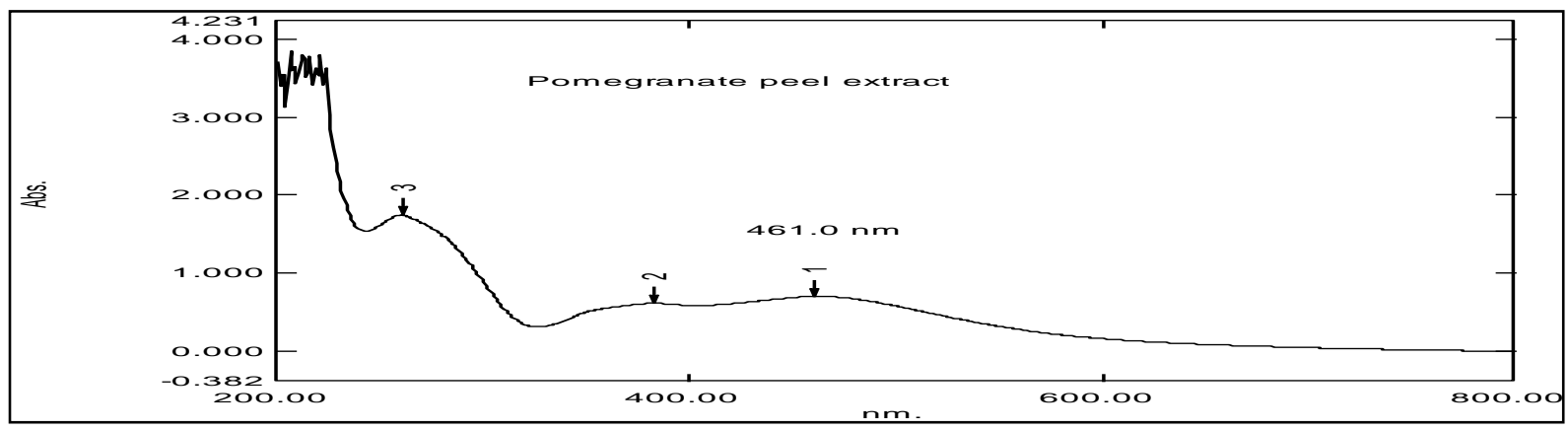

Figure 1: UV-Spectrum of pomegranate peel extract 
Original Article

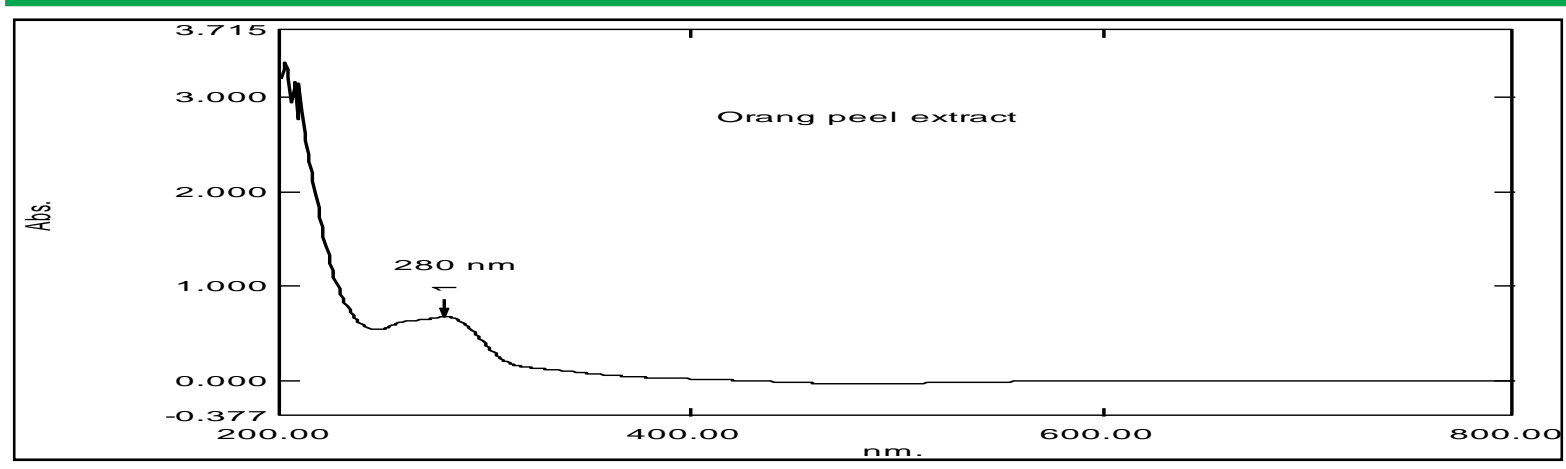

Figure 2: UV-Spectrum of orange peel extract

Table 1: Phyto-chemical analysis of ethanolic extract of pomegranate and orange peel

Phytochemicals

\section{Pomegranate Orange}

Alkaloids

Aminoacide

Tannin

Anthraquinones

Saponins

Potein

Terpenoids

Cardiac glycosides

Note: + = Present, $-=$ Absent

Table 2: Quantitative analysis of pomegranate and orange peel extract

\begin{tabular}{lcc}
\hline Parameters & Pomegranate & Orange \\
\hline Equivalent weight $(\mathbf{m g} / \mathbf{m l})$ & 345.14 & 500.10 \\
Ash content & $30 \%$ & $40 \%$ \\
Moisture content & $72 \%$ & $96.12 \%$ \\
pH & 3.6 & 3.8 \\
\hline
\end{tabular}


The FT-IR spectrum of pomegranate peel extract showed the distinct peak in the range of 3036, 2928, 1734, 1102 and 713. The absorption peaks located mainly at $3036 \mathrm{~cm}^{-1}$ are generally attributed to aromatic or aliphatic C-H stretching, $2928 \mathrm{~cm}^{-1}$ are generally assigned to the alkyl C-H stretching, whereas peaks at 1734,1375 and $1332 \mathrm{~cm}^{-1}$ are due to $\mathrm{C}-\mathrm{O}-\mathrm{O}$ stretching bands, 1102 and $1050 \mathrm{~cm}^{-1}$ are due to $\mathrm{C}-\mathrm{C}$ stretching vibrations, 713 and 624 $\mathrm{cm}^{-1}$ are due to acetylenic $\mathrm{C}-\mathrm{H}$ bending vibrations in the region of $40-4000 \mathrm{~cm}^{-1}$. All the spectrum of pomegranate peel extract are present in the pomegranate peel extract nanoparticles. Hence there was no any shift of functional groups are seen in pomegranate peel extract nanoparticles (Figure $3 \& 4$ ).

Table 3: FTIR peaks of Pomegranate peel extract and peel extract nanoparticles

\begin{tabular}{lll}
\hline Functional group & \multicolumn{2}{l}{ Absorption peaks $\left(\mathbf{c m}^{-\mathbf{1}}\right)$} \\
& $\begin{array}{l}\text { Pomegranate } \\
\text { extract }\end{array}$ & $\begin{array}{c}\text { peel } \\
\text { Pomegranate } \\
\text { extract nanoparticles }\end{array}$ \\
\hline aromatic or aliphatic C-H stretching & 3036 & 3038.31 \\
alkyl C-H stretching & 2928 & 2926.48 \\
C-O-O stretching bands, & 1734,1375 and 1332 & 1338.23 \\
C-C stretching vibrations & 1102 and 1050 & 1008.1 \\
acetylenic C-H bending & 713 and 624 & 896.06 \\
\hline
\end{tabular}

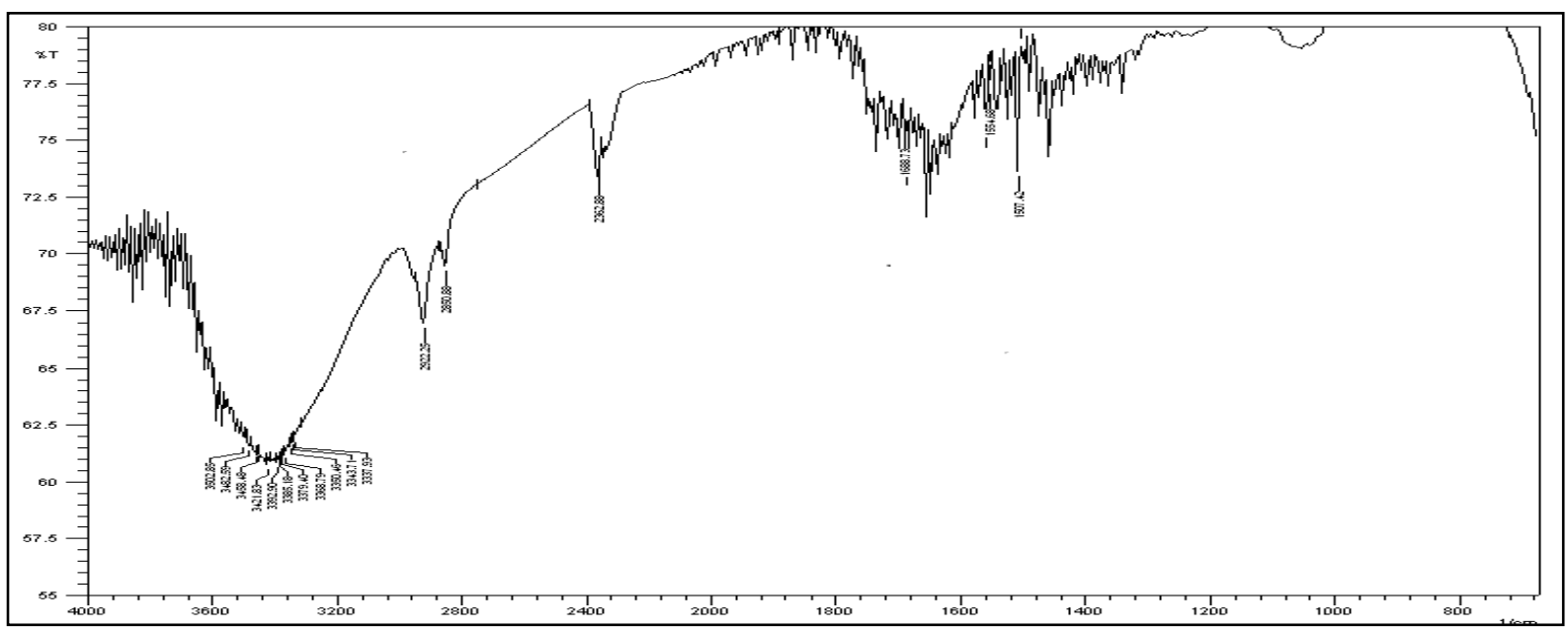

Figure 3: FTIR spectra for pomegranate peel extract 


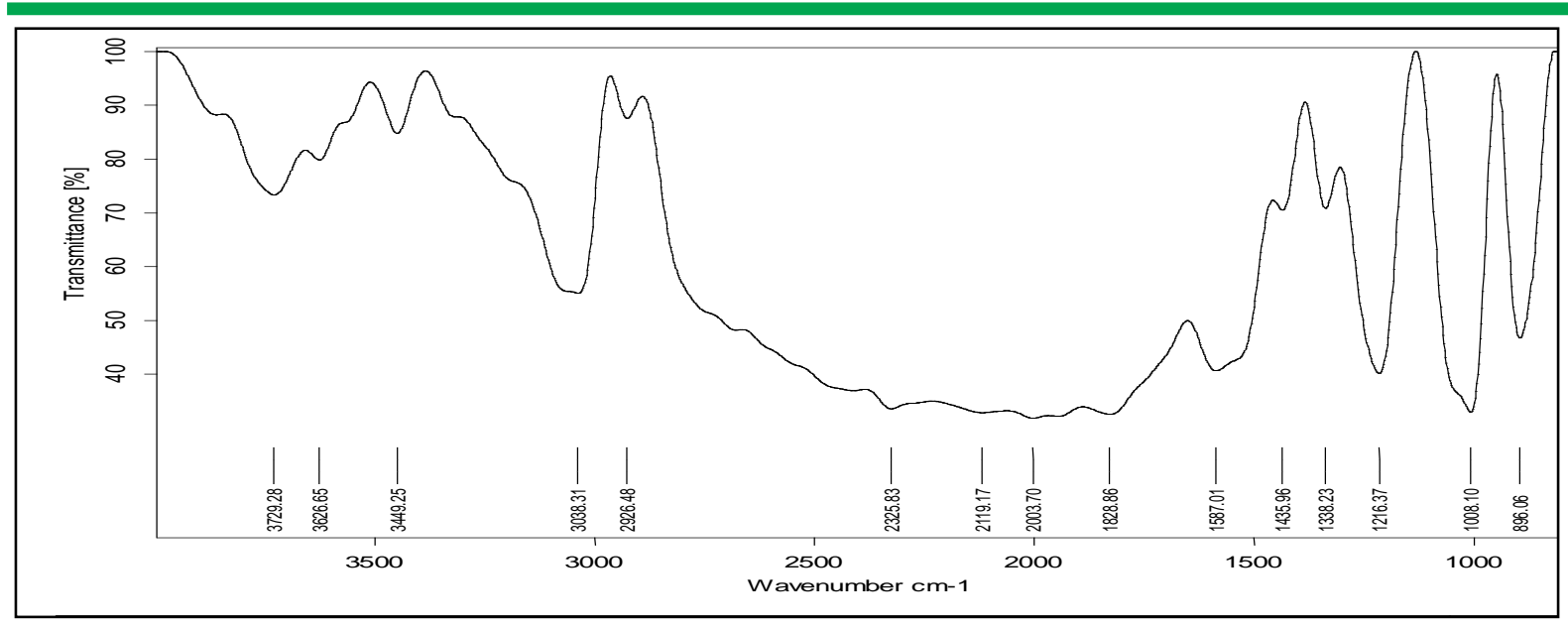

Figure 4: FTIR spectra for pomegranate peel extract nanoparticles

The FT-IR spectrum of orange peel extract showed the distinct peak in the range of 3390, $2355,1649,771,677$, and $424 \mathrm{~cm}^{-1}$ (Fig. 2a). Intense absorption is observed at $1649 \mathrm{~cm}^{-1}$ and is characteristic of the $\mathrm{C}=\mathrm{C}$ stretching aromatic ring. The peak at 3390 and $3388 \mathrm{~cm}^{-1}$ reveals water and $\mathrm{OH}$ absorption frequency. The weak bands at 2355 and $2357 \mathrm{~cm}^{-1}$ indicates carbonyl specific absorption. The peak at 771 and $769 \mathrm{~cm}^{-1}$ corresponds to $\mathrm{C}-\mathrm{H}$ stretching of aromatic compounds. The peak at 677 and $671 \mathrm{~cm}^{-1}$ could be assigned to the $\mathrm{C}=\mathrm{O}$ stretching of carbonyl group. The broad peaks around 424 and $422 \mathrm{~cm}^{-1}$ are related to oxygen from hydroxyl groups. Further the comparison of FT-IR spectrum between the orange peel extract and peel-AgNPs will be done to find out any changes in the position as well as the absorption bands. All the spectrum of orange peel extractis present in the orange peel extract nanoparticles. Hence there was no any shift of functional groups are seen in orange peel extract nanoparticles (Figure 5 \& 6).

Table 4: FTIR peaks of orange peel extract and orange peel extract nanoparticles

\begin{tabular}{lll}
\hline Functional group & \multicolumn{2}{c}{ Absorption peaks $\left(\mathbf{c m}^{-\mathbf{1}}\right)$} \\
& Orange peel extract & $\begin{array}{l}\text { Orange peel } \\
\text { nanoparticles }\end{array}$ \\
\hline C=C stretching aromatic ring & 1649 & 1588.62 \\
OH absorption & 3390 and 3388 & 3388.62 \\
Carbonyl group & 2355 and 2357 & 2256.18 \\
C-H stretching of aromatic & 771 and 769 & 889.11 \\
\hline
\end{tabular}




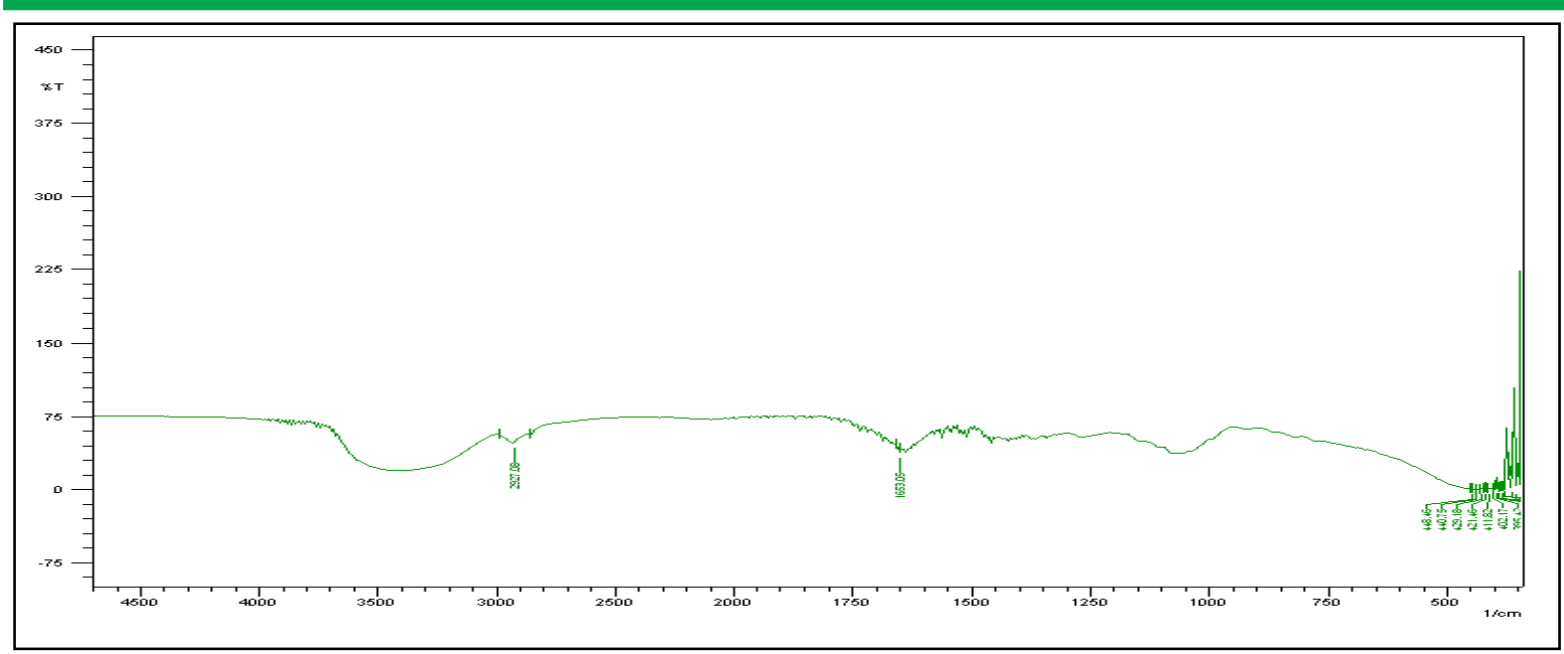

Figure 5: FTIR spectra for orange peel extract

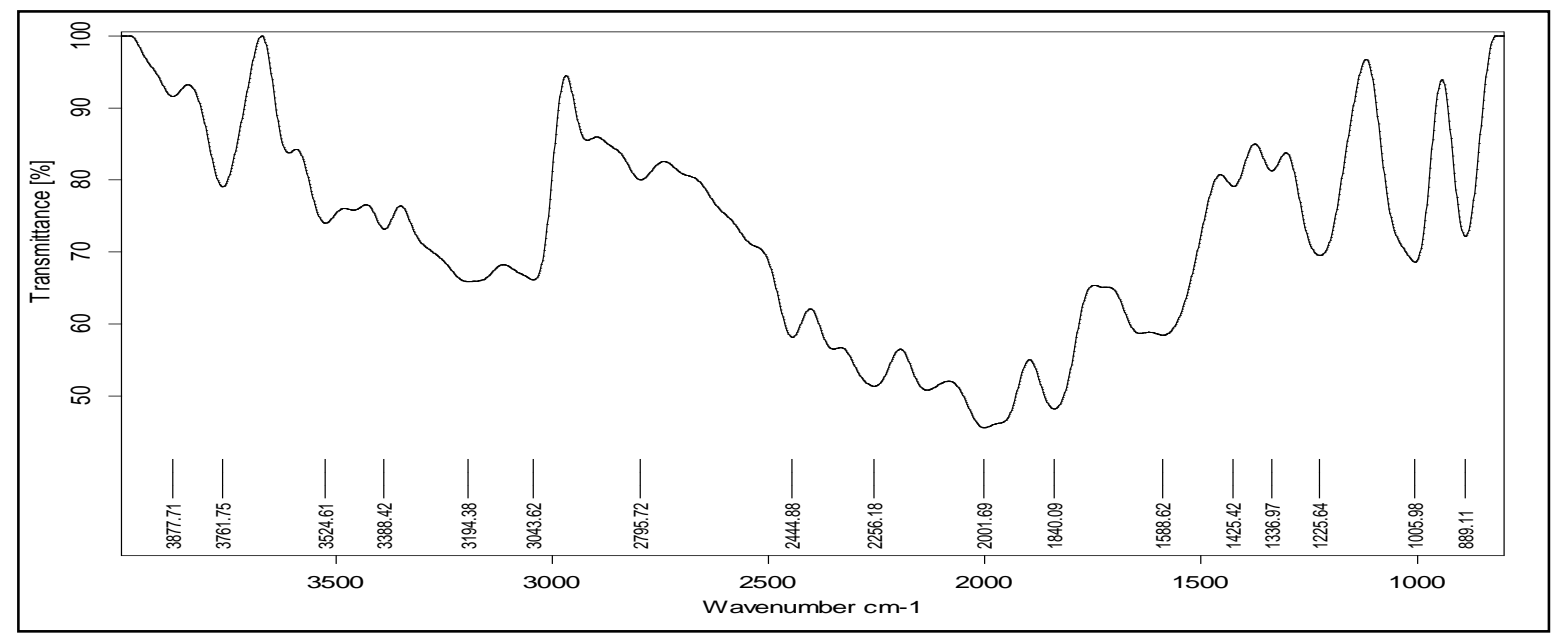

Figure 6: FTIR spectra for orange peel extract nanoparticles

The pomegranate and orange peel extracts silver nanoparticles were subjected to Zeta Potential analysis to determine the surface charge of the nanoparticles and to find out the aggregation behavior. The values of zeta potential for pomegranate peel extract silver nanoparticles were found in the range of $-34.5 \mathrm{mV}$ to $-24.6 \mathrm{mV}$ for pomegranate P50 and pomegranate $\mathrm{P} 20$, respectively. Whereas, in case of orange peel extract nanoparticles showed zeta potential value range from $-32.0 \mathrm{mV}$ to $-21.4 \mathrm{mV}$ for orange $\mathrm{O} 50$ and orange $\mathrm{O} 20$, respectively. Hence all batches of nanoparticles having higher surface charge which indicates there is least chance of aggregation. 
Original Article

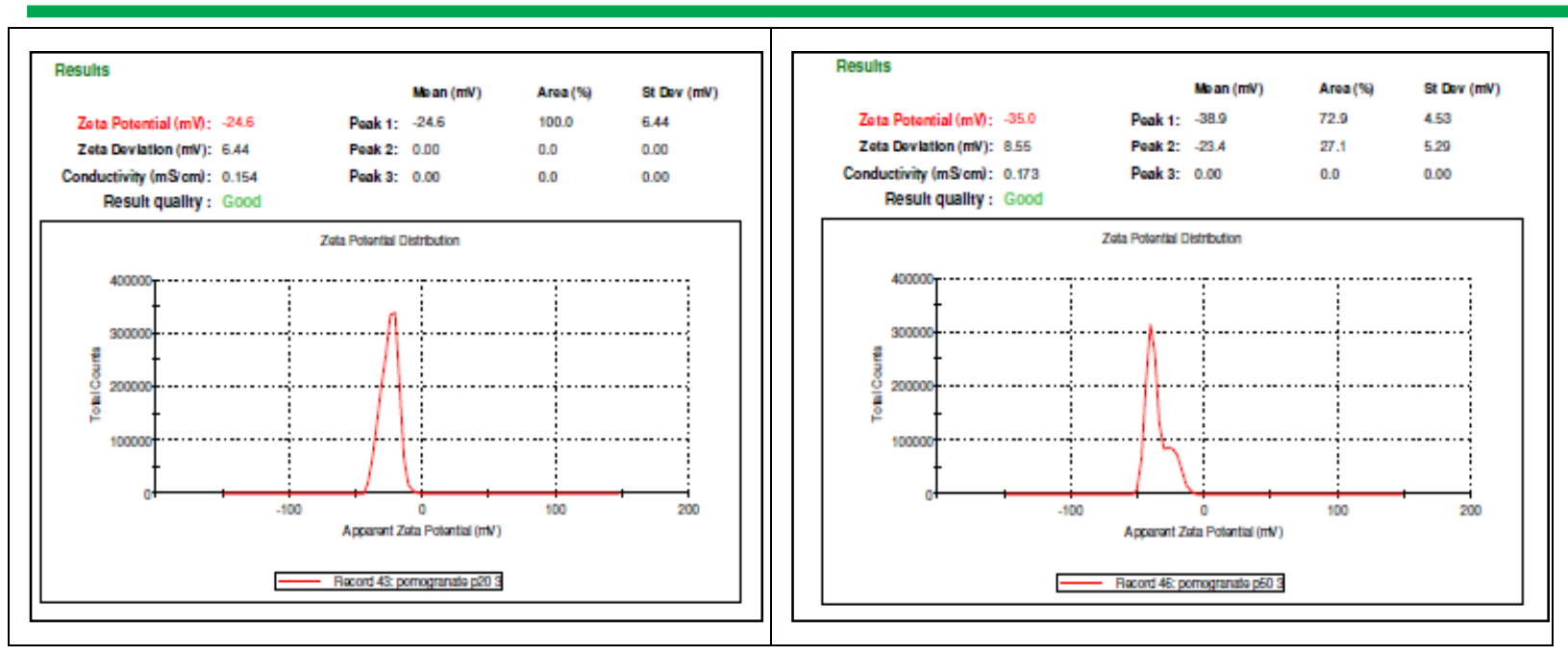

Figure 7: Zeta potential of pomegranate extract silver nanoparticles (P20, P50)

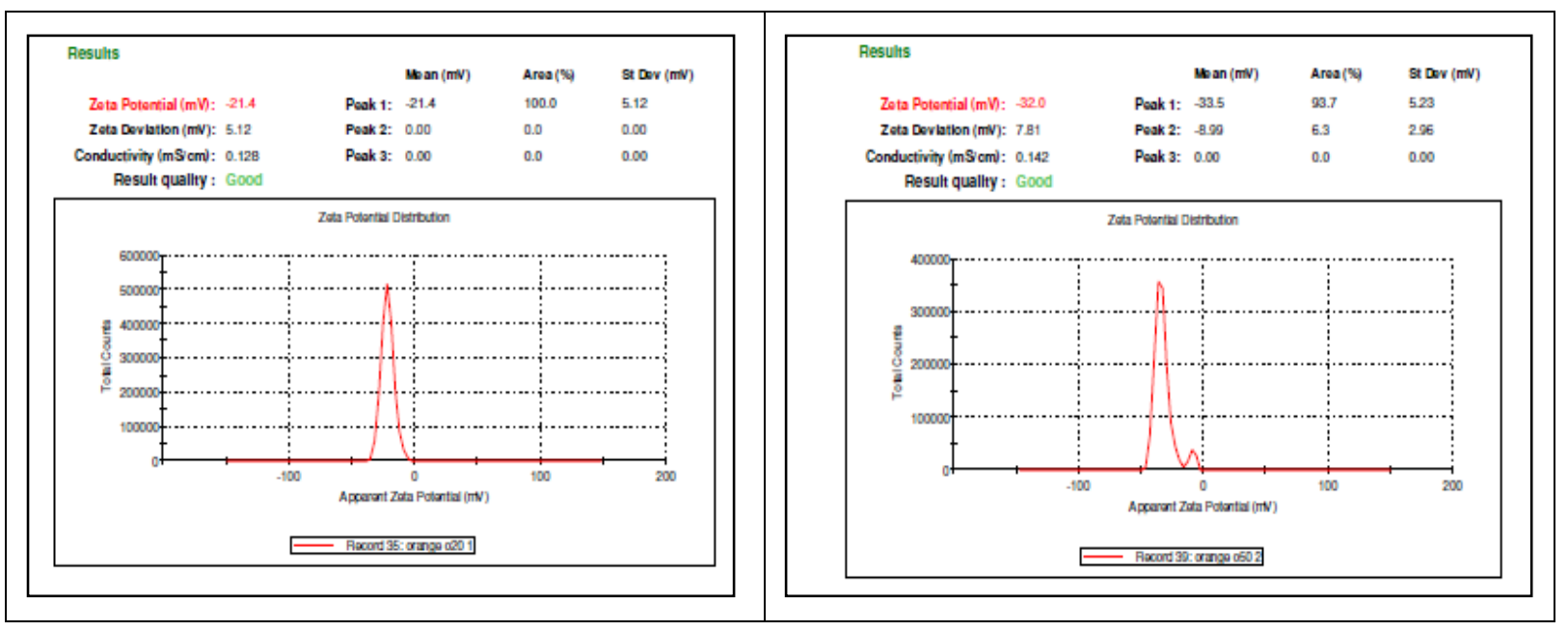

Figure 8: Zeta potential of orange extract silver nanoparticles $(\mathrm{O20}, 050)$

The particle sizes of prepared nanoparticles were determined by using Malvern particle size analyzer. The values of particle size for pomegranate peel extract silver nanoparticles were found in the range of $118.6 \mathrm{~nm}$ to $231.7 \mathrm{~nm}$ for pomegranate P20 and pomegranate P30, respectively. Whereas, in case of orange peel extract nanoparticles showed particle size in the range of $178.8 \mathrm{~nm}$ to $191.6 \mathrm{~nm}$ for orange $\mathrm{O} 20$ and orange O50, respectively. 
Original Article

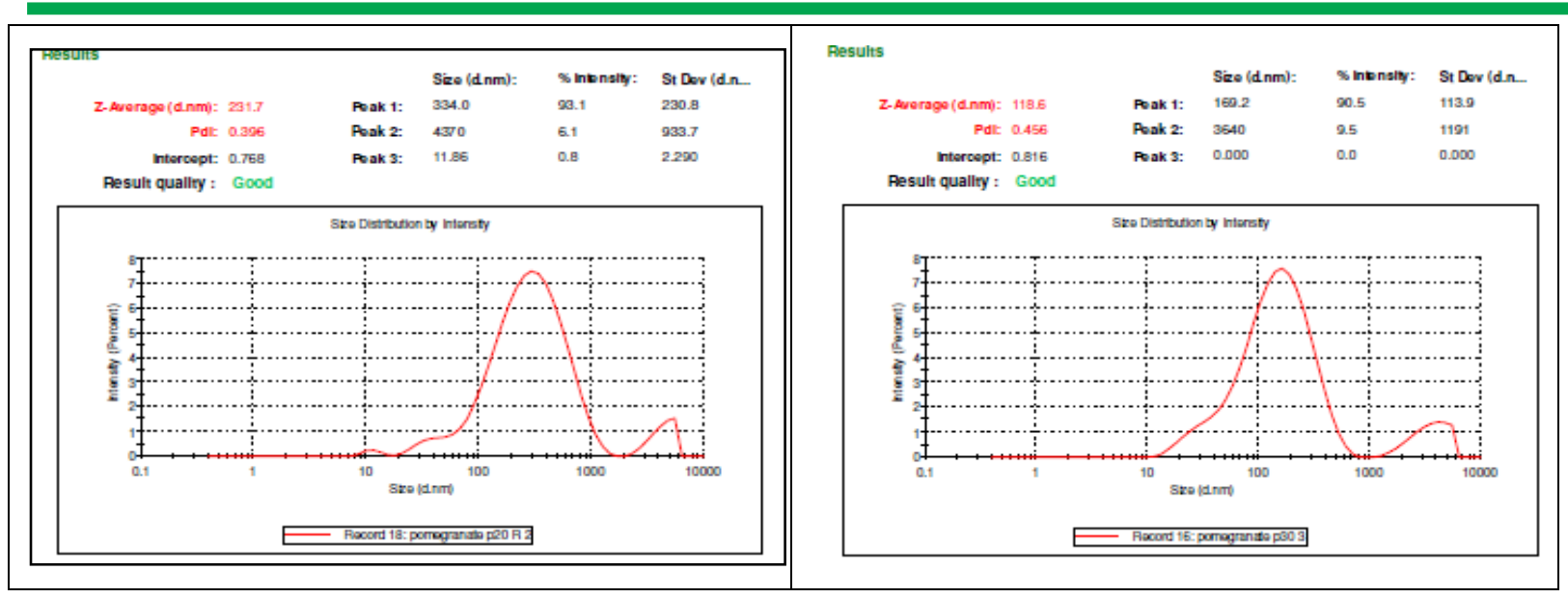

Figure 9: Particle size distribution of pomegranate extract silver nanoparticles (P20, P30)
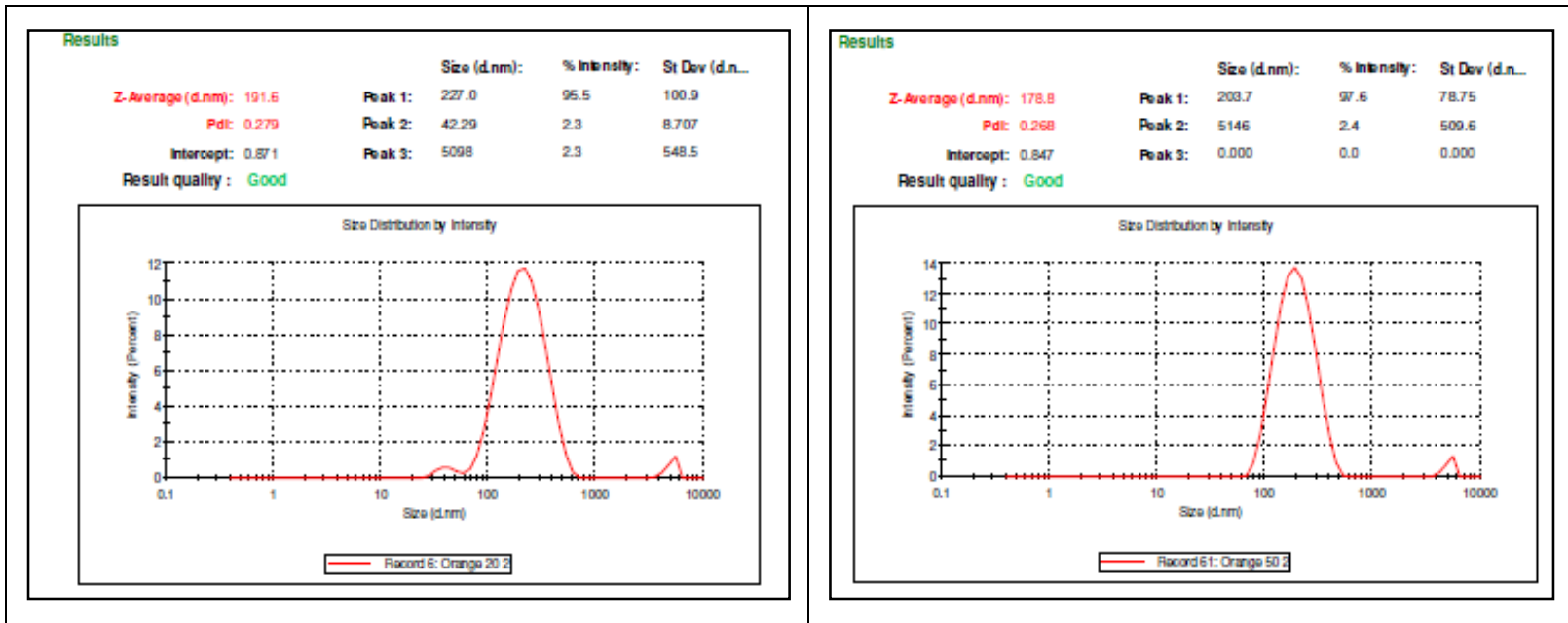

Figure 10: Particle size distribution of orange extract silver nanoparticles $(\mathrm{O20}, \mathrm{O50})$

To confirm the crystalline nature of pomegranate peel extract, X-ray diffraction (XRD) patterns were obtained (Figure 11). The peaks assigned to the diffraction pattern clearly showed peaks corresponding to $2 \theta=11.36^{\circ}, 16.26^{\circ}, 19.04^{\circ}, 27.48^{\circ}, 49.26^{\circ}, 59.56^{\circ}$ and $64.07^{\circ}$.

To confirm the crystalline nature of orange peel extract, X-ray diffraction (XRD) patterns were obtained (Figure 11). The peaks assigned to the diffraction pattern clearly showed peaks corresponding to $2 \theta=9.21^{\circ}, 11.36^{\circ}, 19.42^{\circ}, 38.10^{\circ}$, and $67.44^{\circ}$. 
Original Article

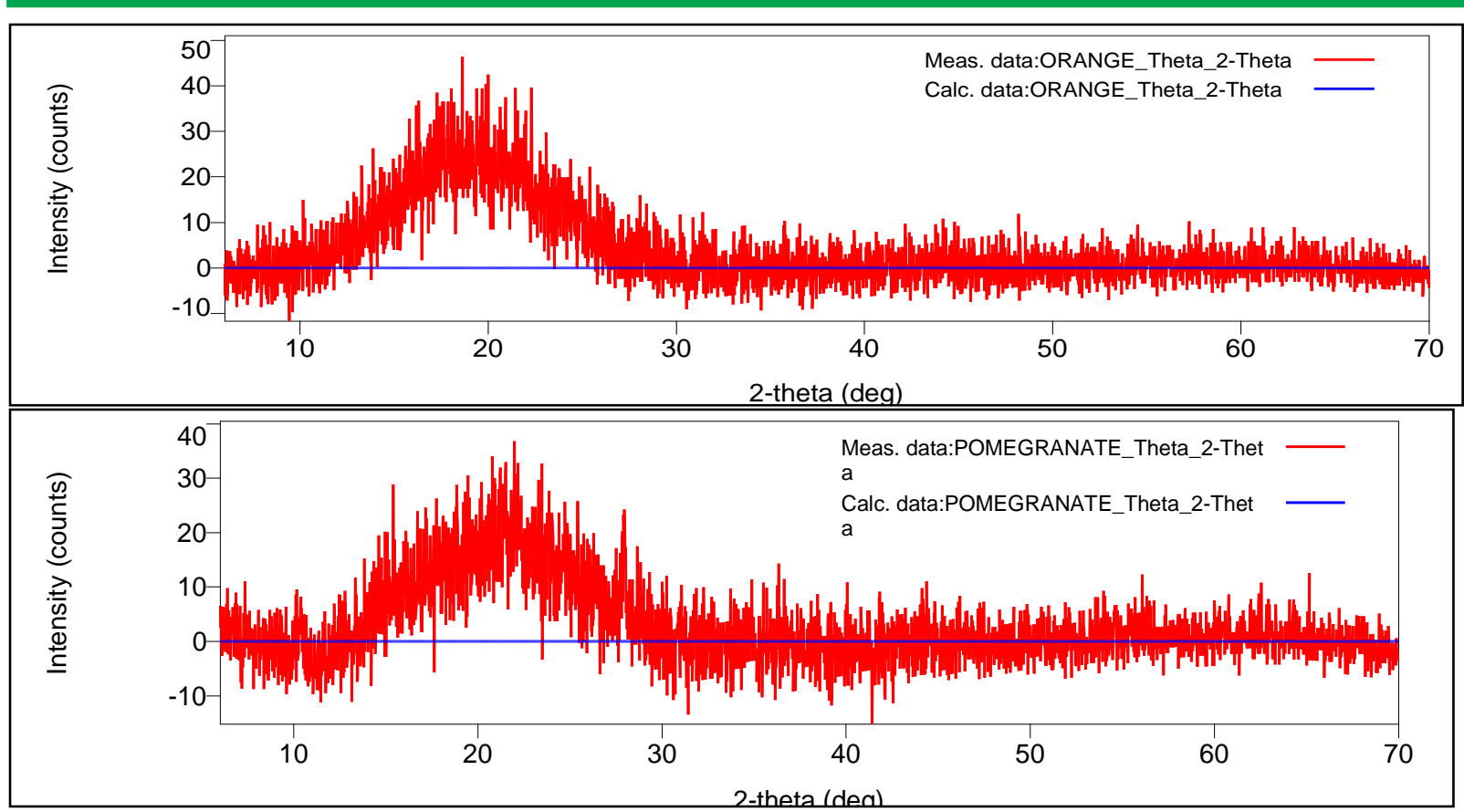

Figure 11: XRD pattern of pomegranate peel extract and orange peel extract

The surface morphology of prepared nanoparticles was determined by using SEM (Hitachi. SEM results clearly showed the formation of nanoparticles and were relatively spherical in shape and also showed there was only a small degree of agglomeration. The largest size of orange peel extract nanoparticles was $94.5 \mathrm{~nm}$ in size whereas pomegranate based nanoparticles had $74.9 \mathrm{~nm}$. The SEM results were shown in figure 12 a (orange peel extract), $12 \mathrm{~b}$ (pomegranate peel extract) and $12 \mathrm{c}$, morphology of peel extract based AgNPs respectively.
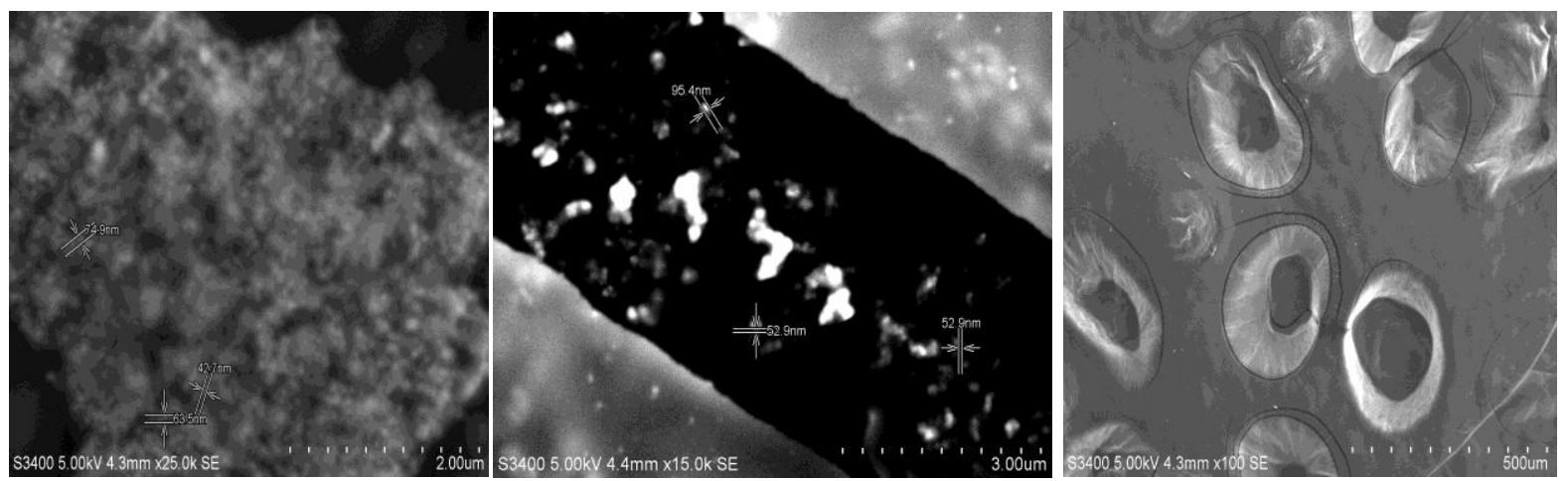

Figure 12: (a) SEM images of AgNPs by orange peel extract, (b) pomegranate peel extract and (c) AgNPs morphology respectively.

Energy dispersive spectrometer (EDS) analysis for the confirmation of elemental silver was carried out for the detection of elemental silver. The EDS microanalysis confirms the presence of AgNPs which is known to provide information on the chemical analysis of the elements or the composition at specific locations. The spectrum analysis reveals signal in the silver region and then confirms the formation of AgNPs. Metallic silver nanocrystals generally show a typical optical absorption peak at approximately $2 \mathrm{keV}$ due to the surface plasmon resonance. The EDS results were shown in figure 13 a for pomegranate peel nanoparticles and $13 \mathrm{~b}$ for orange peel nanoparticles, respectively. 
Original Article

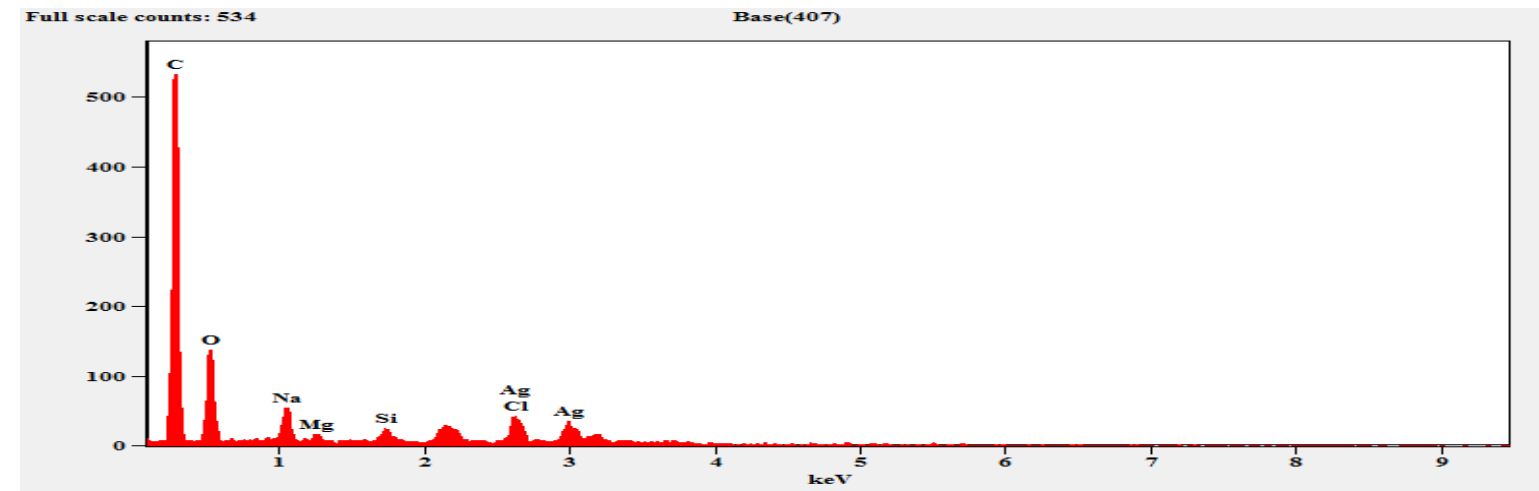

Figure 13 a. EDS pattern of spherical pomegranate peel extract AgNPs prepared

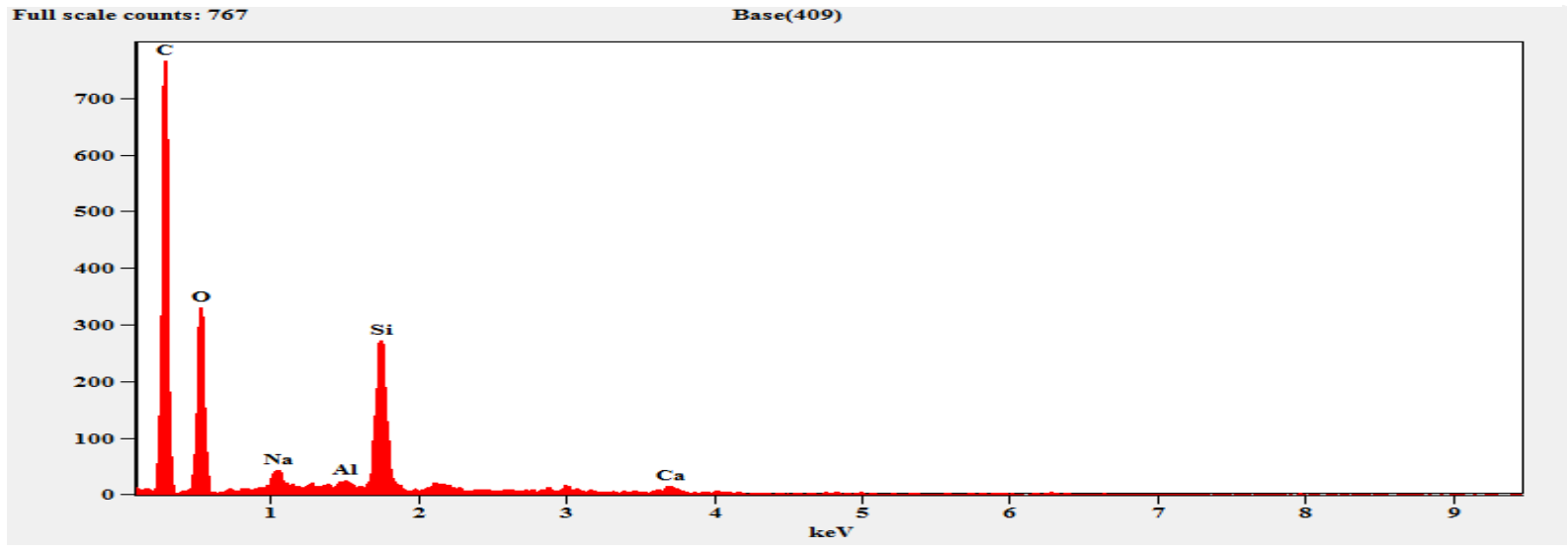

Figure 13 b. EDS pattern of spherical orange peel extract AgNPs prepared 
Original Article

Table 5: Quantitative Results for: Base(407)

\begin{tabular}{cccc}
\hline $\begin{array}{c}\text { Element } \\
\text { Line }\end{array}$ & Weight \% & $\begin{array}{c}\text { Weight \% } \\
\text { Error }\end{array}$ & Atom \% \\
\hline C K & 56.12 & \pm 3.15 & 67.25 \\
O K & 30.86 & \pm 1.38 & 27.76 \\
Na K & 3.94 & \pm 0.47 & 2.46 \\
Mg K & 0.61 & \pm 0.13 & 0.36 \\
Si K & 1.08 & \pm 0.18 & 0.55 \\
Si L & --- & --- & -- \\
Cl K & 2.29 & \pm 0.29 & 0.93 \\
Cl L & --- & --- & -- \\
Ag L & 5.11 & \pm 0.92 & 0.68 \\
Ag M & --- & --- & --- \\
Total & 100.00 & & 100.00 \\
\hline
\end{tabular}


Table 6: Quantitative Results for: Base(409)

\begin{tabular}{cccc}
\hline $\begin{array}{c}\text { Element } \\
\text { Line }\end{array}$ & Weight \% & $\begin{array}{c}\text { Weight \% } \\
\text { Error }\end{array}$ & Atom \% \\
\hline C K & 45.26 & \pm 5.94 & 55.60 \\
O K & 38.92 & \pm 2.13 & 35.88 \\
Na K & 3.18 & \pm 0.45 & 2.04 \\
Al K & 0.43 & \pm 0.13 & 0.24 \\
Si K & 11.10 & \pm 0.30 & 5.83 \\
Si L & --- & --- & -- \\
Ca K & 1.10 & \pm 0.15 & 0.41 \\
Ca L & --- & --- & -- \\
Total & 100.00 & & 100.00 \\
\hline
\end{tabular}

\section{CONCLUSION}

Pomegranate and orange peel extract based nano particles were prepared by chemical complexation method using silver nitrate. Particle size, surface morphology and elemental analysis confirm that prepared formulations were silver particle based nano particle. Further research will be extended for antimicrobial and wound healing activity using suitable animal model. Such herbal based nano particles might be safe, economically cheap and user friendly.

\section{ACKNOWLEDGEMENT}

The authors are thankful to Prof. Dr. B Ramesh, Principal, Sri Adichunchanagiri College of Pharmacy, Bangalore, and Rajiv Gandhi University of health sciences for providing all necessary facilities to carry out this research work.

\section{REFERENCES}

1. Gada R R, Padalia U. Biosynthesis of silver nanoparticles using citrus fruits. Int J Pharm Bio Sci. 2018; 8(1), 146-149.

2. Shanmugavadivu M, Kuppusamy S, Ranjithkumar R. Synthesis of pomegranate peel extract mediated silver nanoparticles and its antibacterial activity. Ame J Adv Drug Deli. 2014; 2(2), 174-182.

3. Tiwari AK, Saha SN, Yadav VP, Upadhyay UK, Katiyar D, Mishra T. Extraction and characterization of pectin from orange peels. Int J Biotech Biochem. 2017;13(1), 39-47.

4. Khan JA, Hanee S. Antibacterial properties of Punica granatum peels.Int J Appl Bio Pharma Tech.2011; 3(2), 23-27. 
5. Santhosh NA, Anto PV and Baby NN. Evaluation on antimicrobial activity of fruit peels of selected citrus species against human pathogenic microorganisms. J Pharm Phyto. 2015;4: 278-281.

6. Wikandari R, Nguyen H, Millati R, Niklasson C, Taherzadeh MJ. Improvement of biogas production from orange peel waste by leaching of limonene. Biomed Res Int. 2015; 1-7.

7. Vinay CH, Ahmed MG, Goudanavar P, Acharya A. Development and characterization of pomegranate-based nanoparticles for drug delivery applications. Int J Pharm Sci Nanotech. 2017; 11(1):3979-3984.

8. Srilatha D, Nasare M, Nagasandhya B, Prasad V, Diwan P. Development and validation of UV spectrophotometric method for simultaneous estimation of hesperidin and diosmin in the pharmaceutical dosage form. ISRN Spectroscopy. 2013;2013, 1-4.

9. Nisha MH, Tamileaswari R, Jesurani S. Analysis of anti-bacterial activity of silver nanoparticles from pomegranate (Punica granatum) seed and peel extracts. Int J Eng Res Technol. 2015,4(4), 1044-1048.

10. Khan JA, Hanee S. Antibacterial properties of Punica granatum peels. Int J Appl Biolo Pharm Tech. 2011; 2(3), 23-27.

11. Al-Saadi NHM, Ahmad NS, Saeed SE. Determination of some chemical compounds and the effect of oil extract from orange peel on some pathogens. J Kerbala Uni. 2009;7(2), 33-39. 